\title{
Elicitation of Valerenic Acid in the Hairy Root Cultures of Valeriana officinalis L (Valerianaceae)
}

\author{
Mohammad Reza Dini Torkamani ${ }^{1 *}$, Naser Abbaspour ${ }^{1}$, Morad Jafari ${ }^{2,3}$ and \\ Afsaneh Samadi ${ }^{4}$ \\ ${ }^{1}$ Department of Biology, Faculty of Science, ${ }^{2}$ Department of Plant Breeding and Biotechnology, Faculty of Agriculture, \\ ${ }^{3}$ Depatment of Agricultural Biotechnology, Institute of Biotechnology, University of Urmia, Urmia, ${ }^{4}$ Farhangian University, \\ Fatemeh Al Zahra Pardis, Tabriz, Iran
}

*For correspondence: Email: dr.torkamani@gmail.com; Tel: +9809141477827

Received: 22 July 2013

Revised accepted: 23 March 2014

\begin{abstract}
Purpose: To investigate the effect of magnesium and calcium as abiotic elicitors on Valeriana officinalis hairy roots for scale-up production of valerenic acid.

Methods: Hairy roots were established in different explants of Valeriana officinalis via a mikimopine type strain of Agrobacterium rhizogenes 'A13'. Transgenic status of hairy roots was confirmed by polymerase chain reaction (PCR) analysis of the rolB gene. Hairy roots of 28-day old cultures were exposed to magnesium and calcium (2 to 6-fold concentration of that present in normal Murashige and Skoog (MS) medium for 3 and 7 days. After elicitation, the cultures were grown in MS liquid medium without elicitors for 8 weeks. Valerenic acid content in hairy roots was analysed using high-performance liquid chromatography (HPLC) to determine the best yield conditions.

Results: Transformed cultures showed significant differences $(p<0.05)$ in valerenic acid content. The highest amount of valerenic acid (1.83 $\pm 0.06 \mathrm{mg} / \mathrm{g}$ dry weight $(D W)$ was found in hairy root cultures exposed to 6-fold calcium for 7 days, which was 7.9 times higher than that of control culture $(0.23 \pm 0.01$ $m g / g D W)$.

Conclusion: The results show that concentration and exposure time to elicitors are important factors that affect the production of valerenic acid.
\end{abstract}

Key words: Valeriana officinalis, Agrobacterium rhizogenes, Elicitors, Explants, Hairy roots, Valerenic acid, Calcium, Magnesium, rolB gene, Transgenic

Tropical Journal of Pharmaceutical Research is indexed by Science Citation Index (SciSearch), Scopus, International Pharmaceutical Abstract, Chemical Abstracts, Embase, Index Copernicus, EBSCO, African Index Medicus, JournalSeek, Journal Citation Reports/Science Edition, Directory of Open Access Journals (DOAJ), African Journal Online, Bioline International, Open-J-Gate and Pharmacy Abstracts

\section{INTRODUCTION}

Valerian (Valeriana officinalis $L$ ) native to Europe and Asia is an important medicinal plant which, due to its mild sedative action is widely used in traditional medicine [1]. The roots and rhizomes of Valeriana contain the components of the volatile oil, including sesquiterpenoid derivatives (valerenic acid) and Valepotriates (iridoids) [2]. Although the identity of the active components responsible for the beneficial health effects in valerian is still fully uncertain in recent findings the main pharmacological effects have been attributed to the valerenic acid and its derivatives, including acetoxyvalerenic acid and hydroxyvalerenic acid [3, 4].

The development of genetically transformed plant tissue cultures and mainly of roots transformed by Agrobacterium rhizogenes (hairy roots) is a key step in the use of in vitro cultures for the production of secondary metabolites [5]. Hairy roots are characterized by fast growth, 
biosynthetic stability and growth in hormone-free medium [6]. The greatest advantage of hairy roots is that their cultures often exhibit approximately the same or greater biosynthetic capacity for secondary metabolite production as compared to their mother plants. Increase in valepotriates content in hairy roots of some Valeriana species has been reported $[7,8]$.

Medicinal plants have been widely explored for hairy root culture and their bioactive principles [9]. Elicitors are compounds which, when added in small concentrations to a living cell culture, induce the biosynthesis of specific secondary metabolites [10] and has been successfully used to induce and enhance accumulation of secondary metabolites in many plant species [11-13]. It is known that jasmonic acid along with $\mathrm{Ca}^{2+}$ play important role in the regulation of signaling network in the response to pathogen attacks [14]. Moreover, the addition of exogenous calcium or jasmonic acid can also simulate pathogen-induced plant defense responses. Successful induction of valepotriate has been reported in adventitious roots of Valeriana amurensis by biotic and abiotic elicitors [15]. The effect of elicitors depends on several parameters such as elicitor concentration, age of culture at the time of elicitation, cell line and duration of elicitor exposure. With references to the role of valerenic acid as important chemical factor responsible for the sedative effect in human [16] in the present study we made an effort to establish a hairy root culture for largescale production of valerenic acid in Valeriana officinalis $\mathrm{L}$ using $\mathrm{Ca}^{2+}$ and $\mathrm{Mg}^{2+}$ salts as abiotic elicitors with different concentrations at time periods of 3 and 7 days.

\section{EXPERIMENTAL}

\section{Chemicals and plant material}

MS medium was purchased from Duchefa (The Netherlands); Magnesium sulfate and Calcium chloride from Sigma-Aldrich. Valerenic acid standard was from Merck. The seeds of $V$. officinalis were provided by Mr. Moddares, CEO of a seed company, in Isfahan Province, Iran in late August 2011.

\section{Establishment and molecular confirmation of hairy roots}

Hairy roots with more than four lateral branches were obtained after transformation with strain 'A13' of $A$. rhizogenes. Maintenance conditions of hairy roots and their induction have been explained in a previous study [17]. The extraction of DNA from both hairy roots and untransformed roots (control) was carried out using the CTAB method [4]. Then PCR analysis used for confirming the transgenic nature of the roots corresponding gene-specific primer pairs. The primer sequences 5'-TTAGGCTTCTTTCTTCA GGTTTACTGCAGC--3' and 5'-TGGATCCCAAA TTGCTATTCCTTCCACGA-3' were designed based on a 780-bp portion of the rolB genes. The primers 5'-ATGCCCGATCGAGCTCAAGT-3' and 5'-CCTGACCCAAACATCTCGGCTGCCCA-3'

were designed also based on the virD gene from the not-transferred virulence region of the $A$. rhizogenes $\mathrm{Ri}$ plasmid. PCR reaction profiles involved: initial denaturation at $94{ }^{\circ} \mathrm{C}$ for $5 \mathrm{~min}$, 35 cycles of denaturation at $94{ }^{\circ} \mathrm{C}$ for $1 \mathrm{~min}$, annealing at $58{ }^{\circ} \mathrm{C}$ for $1 \mathrm{~min}$, extension at $72{ }^{\circ} \mathrm{C}$ for $1 \mathrm{~min}$, a final extension at $72{ }^{\circ} \mathrm{C}$ for $10 \mathrm{~min}$. The amplified DNAs were analysed on $0.8 \% \mathrm{w} / \mathrm{v}$ agarose - ethidium bromide gels, applying a constant voltage of $80 \mathrm{~V}$ for $90 \mathrm{~min}$.

\section{Elicitation}

The study of the effectiveness of two abiotic elicitors was carried out with magnesium and calcium at various levels; 2-, 4- and 6-fold of their concentrations in the normal MS medium, $\left(\mathrm{MgSO}_{4}=740 \mathrm{mg} / \mathrm{g}, \mathrm{CaCl}_{2}=880 \mathrm{mg} / \mathrm{g}\right),\left(\mathrm{MgSO}_{4}\right.$ $\left.=1480 \mathrm{mg} / \mathrm{g}, \mathrm{CaCl}_{2}=1760 \mathrm{mg} / \mathrm{g}\right)$ and $\left(\mathrm{MgSO}_{4}=\right.$ $2220 \mathrm{mg} / \mathrm{g}, \mathrm{CaCl}_{2}=2640 \mathrm{mg} / \mathrm{g}$ ), respectively. For elicitation, 28-day old hairy root cultures were transferred to prepared elicitation media at two time periods of 3 and 7 days. All treatments were done in triplicate. After elicitation, the hairy roots were harvested and placed in a fresh liquid MS basal medium as done for untreated roots. All cultures were inoculated in the dark at $25^{\circ} \mathrm{C}$ in $25 \mathrm{ml}$ medium in $100 \mathrm{ml}$ flasks and sub-cultured every two weeks in order to obtain sufficient biomass for valerenic acid analysis.

\section{Measurement of hairy root growth}

Hairy roots were harvested from the culture media by filtration and measured in terms of growth (fresh and dry weight) as follows; fresh weight of samples were determined after drying by a hair dryer, then they were lyophilized and analyzed for dry weight. The results were represented by the mean \pm standard error (SE).

\section{Extraction of valerenic acid}

Valerenic acid was extracted from lyophilized and powdered roots (approx. $0.2 \mathrm{~g}$ ) thrice with 5 $\mathrm{ml}$ of $70 \% \mathrm{MeOH}$ using sonication for $10 \mathrm{~min}$ and then the filterate was diluted to $15 \mathrm{ml}$ with $\mathrm{MeOH}$ and mixed. All samples were filtered through a Millex-LH filter with $0.45 \mu \mathrm{m}$ pore size (Millipore, Bedford, MA, USA) for reverse-phase 
high-performance liquid chromatography (HPLC) analysis as described in previous studies [18].

\section{Valerenic acid quantification}

HPLC was performed on the Knauer instrument (Germany) with a Spectra UV-K 2501 detector. The optimum HPLC condition for separation was a $0.5 \%$ phosphoric acid: methanol mixture (27:73) as mobile phase by a flow rate of 1.5 $\mathrm{ml} / \mathrm{min}$ and a Nucleosil column 100 (C18; $250 \times$ $3 \mathrm{~mm})$ with a pre-column $(25 \times 4.6 \mathrm{~mm}$, particle size $5 \mu \mathrm{m})$. Detection wavelength was used at $225 \mathrm{~nm}$ and the injection volume was $10 \mu \mathrm{l}$. Standard solution was prepared by dissolving valerenic acid in methanol to obtain solutions with different concentrations in the range of $0.01562-1 \mu \mathrm{g} / \mathrm{ml}$. The calibration curves were established based on measuring their respective peak areas.

\section{Statistical analysis}

Data for root weight were set up in a completely randomized design (CRD) with three replicates per treatment. Variation within the elicitors were evaluated and analyzed by one way ANOVA test using SPSS (version 16). Significance level for comparison of mean differences was $p<0.05$.

\section{RESULTS}

\section{Establishment of hairy root cultures}

Hairy root cultures of $V$. officinalis were initiated by inoculation of root, hypocotyl and leaf explants with strain 'A13' of $A$. rhizogenes. These roots exhibited characteristics typical of transformed roots, that is, extensive lateral branch, rapid growth and lack of geotropism (Fig. 1).

Whereas no adventitious roots formed from the control explants. Leaf explants were highly susceptible to infection by strain 'A13' of $A$. rhizogenes, as shown by the high percentage (93 $\%$ ) of hairy roots that emerged. In contrast, hypocotyl explants exhibited the lowest infection frequency (63\%) (data not shown). Also there was a variation in the site of emergence and in the number of hairy roots per explants (Fig. 2).
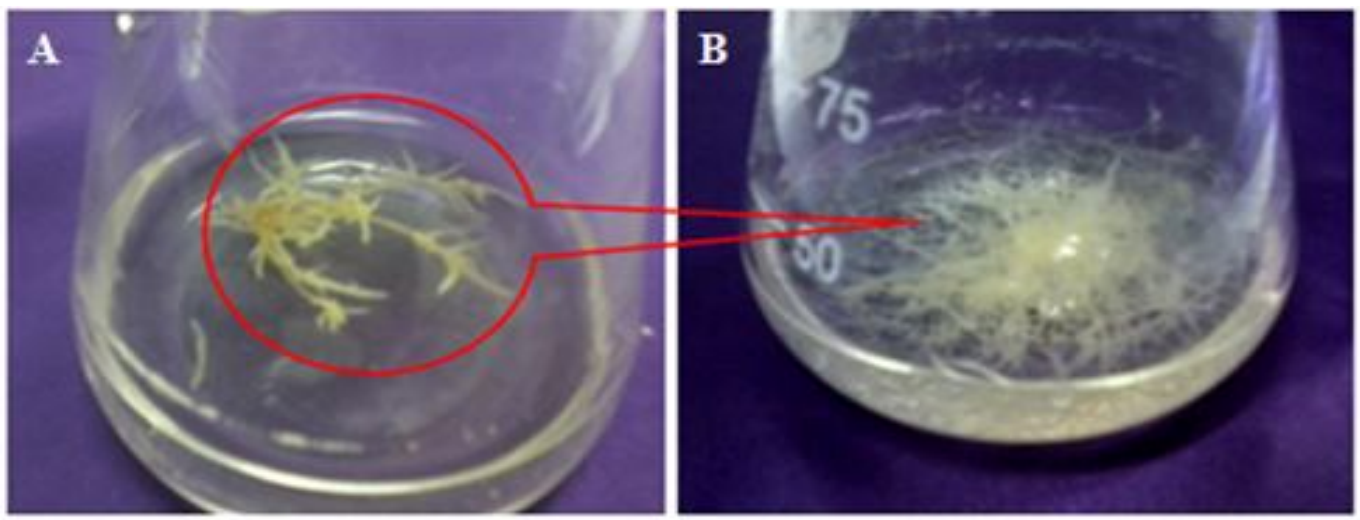

Fig 1: A: Hairy roots before growth measuring B: Growth of the hairy roots after third subculture (sub-culturing was carried out every 14 days)
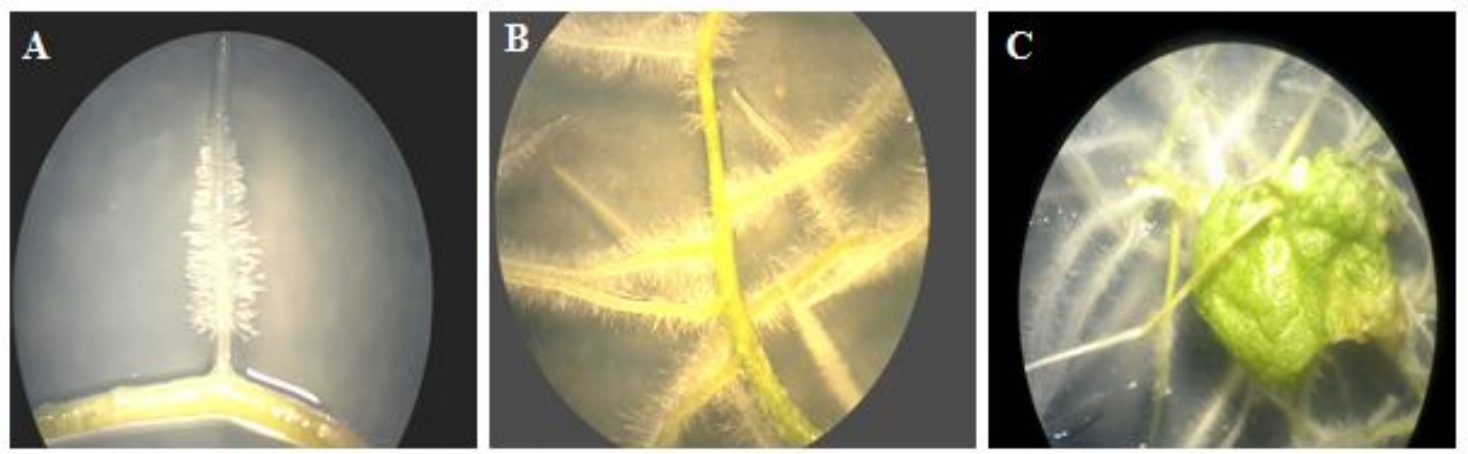

Fig 2: Variation in the number and the site of emergence of the hairy roots induced on explants of the $V$. officinalis one week after inoculation by $A$. rhizogenes strain 'A13'; $A=$ emergence of hairy root from hypocotyl explant; $B=$ emergence of several hairy roots from root explant; $C=$ emergence of the thin hairy roots from leaf explant 

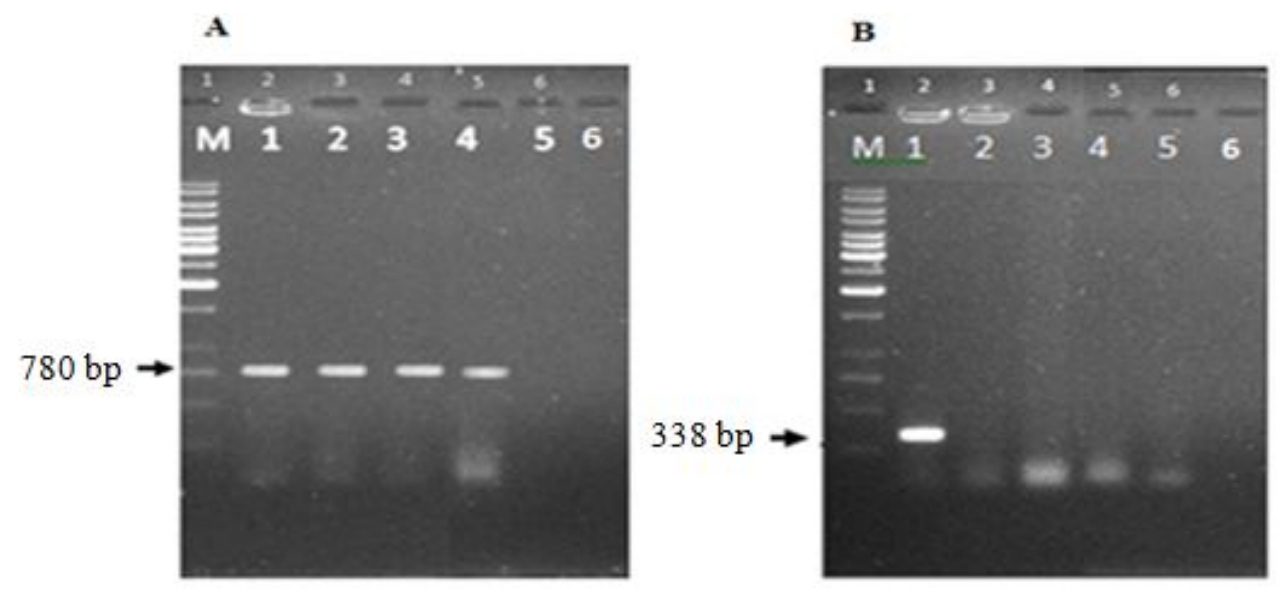

Fig 3: $\mathbf{A}=\mathrm{PCR}$ analysis for hairy roots of $V$. officinalis using the ro/B genes specific primers. $M$ : $1 \mathrm{~Kb}$ DNA Ladder, 1: Ri plasmid from $A$. rhizogenes strain 'A13' as a positive control, 2- 4 : Transgenic hairy roots induced on hypocotyl, root and leaf explants, 5: Wild plant root as first negetive control, 6: Non-DNA template PCR reaction as second negative control. $B=P C R$ analysis for hairy roots of $V$. officinalis using the virD genes specific primers. M: $1 \mathrm{~Kb}$ DNA Ladder, 1: Ri plasmid from $A$. rhizogenes strain 'A13' as a positive control, 2-4: Transgenic hairy roots induced on hypocotyl, root and leaf explants, 5: Wild plant root as first negetive control, 6 : Non-DNA template PCR reaction as second negative control

Table 1: Effect of various concentrations of $\mathrm{Ca}^{2+}$ and $\mathrm{Mg}^{2+}$ on the fresh and dry weight

\begin{tabular}{lccc}
\hline Day & Elicitor $(\mathbf{m g} / \mathbf{m L})$ & FW $(\mathbf{g})$ & DW $(\mathbf{m g})$ \\
\hline \multirow{3}{*}{3} & Control & $4.36 \pm 0.26$ & $289 \pm 6.9$ \\
& $\mathrm{Mg}-740$ & $4.06 \pm 0.16$ & $267 \pm 2.5$ \\
& $\mathrm{Mg}-1480$ & $4.30 \pm 0.30$ & $280 \pm 2.4$ \\
7 & $\mathrm{Mg}-2220$ & $4.13 \pm 0.32$ & $272 \pm 3.2$ \\
& $\mathrm{Mg}-740$ & $4.16 \pm 0.29$ & $276 \pm 4.1$ \\
& $\mathrm{Mg}-1480$ & $4.26 \pm 0.24$ & $277 \pm 2.7$ \\
3 & $\mathrm{Mg}-2220$ & $3.55 \pm 0.05$ & $272 \pm 1.8$ \\
& $\mathrm{Ca}-880$ & $4.23 \pm 0.17$ & $283 \pm 7.4$ \\
& $\mathrm{Ca}-1760$ & $4.06 \pm 0.20$ & $275 \pm 4.9$ \\
7 & $\mathrm{Ca}-2640$ & $4.26 \pm 0.19$ & $287 \pm 3.7$ \\
& $\mathrm{Ca}-880$ & $4.56 \pm 0.28$ & $284 \pm 3.2$ \\
& $\mathrm{Ca}-1760$ & $4.40 \pm 0.29$ & $281 \pm 5.2$ \\
& $\mathrm{Ca}-2640$ & $4.20 \pm 0.40$ & $263 \pm 5.2$ \\
\hline
\end{tabular}

Each value represents mean \pm SE of samples

Detection of relevant transgenes in the hairy root In this study, the presence of rolB gene in the hairy root lines was confirmed by PCR analysis (Fig $3 A$ ) using specific primers of the rolB gene. To diagnose the presence of any remaining agrobacteria in the roots was used from the virD gene, located outside the T-DNA (Fig 3B).

\section{Effect of elicitors on hairy root growth}

The effect of $\mathrm{Ca}^{2+}$ and $\mathrm{Mg}^{2+}$ salts on the growth of hairy roots culture of $V$. officinalis was evaluated by measurement of the fresh and dry weight of the roots 3 and 7 days after treatment (Table 1). The results showed that different concentrations of the metal ions at time periods of exposure 3 and 7 days did not significantly affect the growth of hairy roots.

\section{Effect of elicitors on valerenic acid accumulation}

The effect of abiotic elicitors on the accumulation level of valerenic acid was then examined. HPLC analysis demonstrated that the addition of these metal ions led to significant increases of valerenic acid contents at all concentrations (except at the concentration of $880 \mathrm{mgl}^{-1}$ of the calcium) as compared to control culture (Fig 4). In particular, the highest concentration (6-fold) of calcium at exposure time of 7 days (Fig 4A) was shown to induce the highest amount of valerenic acid $(1.83 \pm 0.06 \mathrm{mg} / \mathrm{g} \mathrm{DW})$. Moreover, the treatment of $V$. officinalis hairy roots with the highest concentration (6-fold) of magnesium at exposure time of 7 days resulted in the accumulation of valerenic acid at $1.11 \pm 0.03$ $\mathrm{mg} / \mathrm{g}$ DW (Fig 4B). These levels of valerenic acid were 7.9 and 4.2 -fold higher than that of nonelicited control $(0.23 \pm 0.01 \mathrm{mg} / \mathrm{g} \quad \mathrm{DW})$, respectively. In contrast, the treatment with calcium only slightly decreased the amount of valerenic acid $(0.21 \pm 0.03 \mathrm{mg} / \mathrm{g} \mathrm{DW})$ at the concentration of $880 \mathrm{mg} / \mathrm{g}$ at exposure time of 3 days (Fig 4A). 

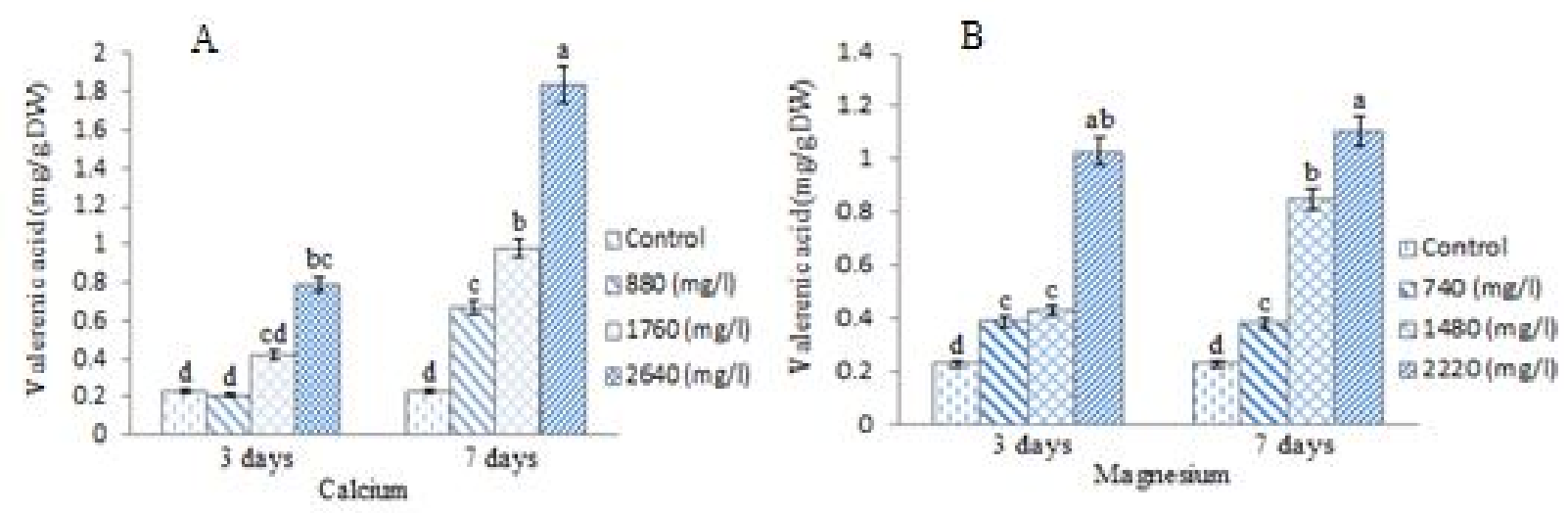

Fig 4: Valerenic acid accumulation in the hairy root cultures grown under the influence of abiotic elicitors at exposure times of 3 and 7 days. The bars represent means \pm SE. Bars followed by different letters are significantly different $(p<0.05) ; a, b$, and d grouping = comparison of means (Duncan's test)

\section{DISCUSSION}

The results indicate that wild type strain of $A$. rhizogenes used in this study was able to impressively induce hairy roots on explants that can be used for mass production of hairy roots in $V$. officinalis. Successful production of hairy roots via wild type strain 'A13' of $A$. rhizogenes has also been reported for several medicinal plant species by other workers $[17,19]$. PCR method can be used simply for detecting T-DNA sequences [17]. In the selected transgenic hairy root lines, a sharp band of 780-bp was amplified, but no such amplification was observed in the untransformed root (negative control) sample. This result indicated that $V$. officinalis is susceptible for transformation with Agrobacterium rhizogenes strain ' $A 13$ '. The rolB gene is absolutely essential for induction of hairy roots, even when to express alone [20]. The virD gene, located outside the T-DNA, is diagnostic for the presence of any remaining agrobacteria in the root tissue. The negative results of PCR amplification for the virD gene demonstrated that no bacterial DNA was involved in rolB amplification leading to false positives (Fig 3B). This result indicates that $V$. officinalis is susceptible for transformation with $A$. rhizogenes strain 'A13' and explants respond quite efficiently to transformation by $A$. rhizogenes.

After elicitation, the hairy roots were transferred to the fresh liquid MS medium. Then the effect of $\mathrm{Ca}^{2+}$ and $\mathrm{Mg}^{2+}$ salts on the growth of $\mathrm{V}$. officinalis hairy roots was evaluated by measurement of the fresh and dry weight of the roots 8 weeks after culture in $250 \mathrm{ml}$ flask. The results obtained are in agreement with earlier reports [15]. The age of the subculture plays an important role in the production of bioactive compounds by elicitation. Elicitation has opened up a new area of research. Among numerous strategies for increasing of accumulation of secondary metabolites from plant cell cultures. A few studies focused on the production enhancement of valerenic acid in in vitro cell cultures of some species of Valeriana using plant growth regulators and elicitors $[8,15,21]$, but to our knowledge, there are no publications about elicitation of valerenic acid from $V$. officinalis hairy roots. In this study, this approach was used for the first time to enhance the yield of valerenic acid using four different concentrations of calcium and magnesium salts at time periods of exposure 3 and 7 days. It has been reported that tanshinone production in Salvia miltiarrhiza hairy roots induced by $\mathrm{Ag}^{+}$treatment [22]. Also elicitation of Linum album cell suspension culture with some abiotic elicitors such as $\mathrm{Ag}^{+}, \mathrm{Pb}^{2+}$ and $\mathrm{Cd}^{2+}$, only silver enhanced the content of podophyllotoxin in the contact period of $48 \mathrm{~h}$ [23]. Elicitation may activate multiple genes responsible for plant defensive responses, leading to enhancement of secondary metabolite production. Induced plant defensive responses involve a network of signal transduction triggered via the recognition of elicitor molecules by specific plant receptors [14]. Root cultures of Beta vulgaris $\mathrm{L}$ when exposed with high concentrations of $\mathrm{Ca}^{2+}$ and $\mathrm{Mg}^{2+}$ (2- to 6-fold of that present in the MS basal medium) led to enhancement of peroxidase [24]. These findings indicate that the optimal concentrations of $\mathrm{Ca}^{2+}$ and $\mathrm{Mg}^{2+}$ are required to maximize induction of secondary metabolites. Enhancement of accumulation of secondary metabolites by $\mathrm{Ca}^{2+}$ and $\mathrm{Mg}^{2+}$ could be attributed to their reported roles as both nutrient and secondary signaling 
molecules in the responses that follow elicitation $[10,25]$. It is known that calcium plays important role in the regulation of signaling network in response to pathogen attacks, and its exogenous addition to plant cell or intact plants led to biosynthesis of a wide range of plant secondary metabolites [14,26]. In the present study, valerenic acid, as an important metabolite in biosynthesis of valepotriates was accumulated in hairy root cultures by $\mathrm{Ca}^{2+}$ and $\mathrm{Mg}^{2+}$ ions. Therefore, hairy root lines obtained in this study can be the desirable organs for biosynthesis/accumulation of this metabolite.

\section{CONCLUSION}

It has been shown that $\mathrm{Ca}^{2+}$ and $\mathrm{Mg}^{2+}$ salts, as abiotic elicitors, significantly enhance valerenic acid production in $\mathrm{V}$. officinalis hairy roots. With regards to easy access to abiotic elicitors, in particular, ions are more effective for large-scale production of the desired compounds, compared with biotic elicitors that need several processing steps. The high concentrations of $\mathrm{Ca}^{2+}$ and $\mathrm{Mg}^{2+}$ are essential requirements for valerenic acid production in hairy root cultures of $V$. officinalis.

\section{ACKNOWLEDGEMENT}

The authors thank Dr. Malboobi (National Instiatute of Genetic Engineering and Biotechnology, Iran) for kindly providing the $A$. rhizogenes 'A13' strain. Thanks are also extended to the Biotechnology Institute of Urmia University (BIUU) for its laboratory available to execute this study.

\section{REFERENCES}

1. Deborah S, Ron BW. Effect of postharrest handling on valerenic acid content fresh valerian (Valeriana officinalis) root. J Sci Food and Agri 2006; 86: 107110.

2. Bos R, Woerdenbag HJ, Desmet PAGM, Scheffer JJC. Adverse Effects of Herbal Drugs. Spri Ver Berlin 1997; 3: 165-180.

3. Singh G. Elicitation-Manipulating and enhancing secondary metabolite production. Plant cell and tissue culture for the production of food ingredients. New York USA Klu Aca 1999; 21: 121-128.

4. Khan S, Irfan QM, Kamaluddin AT, Abdin MZ. Protocol for isolation of genomic DNA from dry and fresh roots of medicinal plants suitable for RAPD and restriction digestion. Afr J Biot 2007; 6: 175-178.

5. Kim Y, Wyslouzil B, Weathers PJ. Secondary methabolism of hairy root cultures in bioreactors. In Vitro Cell Dev PI 2002; 38: 1-10.
6. Srivastava S, Srivastava AK. Hairy root culture for massproduction of high-value secondary metabolites. Crit Rev Bio 2007; 27: 29-43.

7. Banerjee S, Rahman L, Uniyal GC, Ahuja PS. Enhanced production of valepotriates by Agrobacterium rhizogeneses induced hairy root cultures of Valeriana wallichii DC. Plant Sci 1998; 131: 203-208.

8. Caetano CL, Charlwood BV, Gahan PB. The localization accumulation of valepotriates in hairy roots of Valerianella discoidea L. Loi Phyto Anal 1999; 10: 181-186.

9. Guillon S, Tremouillaux-Guiller J, Pati PK, Rideau M, Gantet P. Harnessing the potential of hairy roots: dawn of a new era. Trends Biot 2006; 24: 403-409.

10. Radman R, Saez T, Bucke C, Keshavarz T. Elicitation of plants and microbial cell systems. Bio and App Bioch 2003; 37(1): 91-102.

11. Jaber-Vazdekis $N$, Barres $M L$, Ravelo AG, Zarate $R$. Effects of elicitors on tropane alkaloids and gene expression in Atropa baetica transgenic hairy roots. $J$ Nat Prod 2008; 71: 26-31.

12. Kittipongpatana N, Davis DL, Poter JR. Methyl jasmonate increases the production of valepotriates by transformed root cultures of Valerianella locusta. Plant Cell Tiss Org Cult 2002; 71: 65-75.

13. Georgiev MI, Kuzeva SL, Pavlov Al, Kovacheva EG, Ilieva MP. Elicitation of rosmarinic acid by Lavandula vera cell suspension culture with abiotic elicitors. Wor Mic Bio 2007; 23: 301-304.

14. Van-Huystee R, Roig $M$, Shnyrov G, Valery L, Ivan $Y$. Peroxidase stability related to its calcium and glycans. Phytoch Rev 2004; 3: 19-28.

15. Lei C, Zhen-Yu W, Xiu-Hua Z. Optimization of elicitors and precursors to enhance valtrate production in adventitious roots of Valeriana amurensis. Plant Cell Tiss Org Cult 2012; 108: 411-420.

16. Saeedeh $G$, Somayeh $E$, Hamedh A, Farzaneh $N$, Mahmoud M. Qualitative and quantitative analysis of some brands of valerian pharmaceutical products. Ethno-Med 2009; 3(1): 61-64.

17. Smadi A, Carapetian J, Heidari R, Jafri M, Hassanzadeh A. Hairy Root Induction in Linum mucronatum ssp. mucronatum, an anti-tumor lignans producing plant. Not Bot Horti Agrobo 2012; 40(1): 125-131.

18. Tania $L$ and Brian CF. In vitro activity of commercial valerian root extracts against human cytochrome P450 3A4. J Phar Pharm Sci 2004; 7(2): 265-273.

19. Ohara A, Akasaka Y, Daimon H, Mii M. Plant regeneration from hairy roots induced by infection with Agrobacterium rhizogenes in Crotalaria juncea $L$. Plant Cell Rep 2000; 19: 563-568.

20. Nilsson O, Olsson $O$. The role of the Agrobacterium rhizogenes rol genes in the formation of hairy roots. Phy Plant 1997; 100: 463-473.

21. Ekhteraei S, Tousia T, Radjabianb H, Ebrahimzadeha V. Enhanced production of valerenic acids and valepotriates in vitro cultures of Valeriana officinalis $L$. Int J Plant Prod 2010; 4: 1735.

Trop J Pharm Res, June 2014; 13(6): 948 
22. Xiuchun G, Jianyong $W$. Tanshinone production and isoprenoid pathway in Salvia miltiorrhiza hairy roots induced by Ag and yeast elicitor. Plant Sci 2005; 168 : 487-491.

23. Shams-Ardakani M, Hemmati S, Mohagheghzadeh $A$. Effect of elicitation on the enhancement of podophyllotoxin biosynthesis in suspension cultures of Linum album. J pharm sci 2005; 13(2): 56-60.

24. Thimmaraju $R$, Bhagyalakshmi $N$, Ravishankar $G A$, Venkatachalam L. Elicitation of peroxidase activity in genetically transformed root cultures of Beta vulgaris L. Electro J Biotech 2006; 9: 1-9.

25. Agostini E, Forchetti SM, Tigier HA. Production of peroxidases by hairy roots of Brassica napus. Plant Cell Tis Org Cult 1997; 47: 177-182.

26. Lukasz K, Elżbieta B, Halina W. Methyl jasmonate effect diterpenoid accumulation in Salvia sclarea hairy root culture in shake flasks and sprinkle bioreactor. Enzyme Microb Technol 2009; 44: 406-410. 